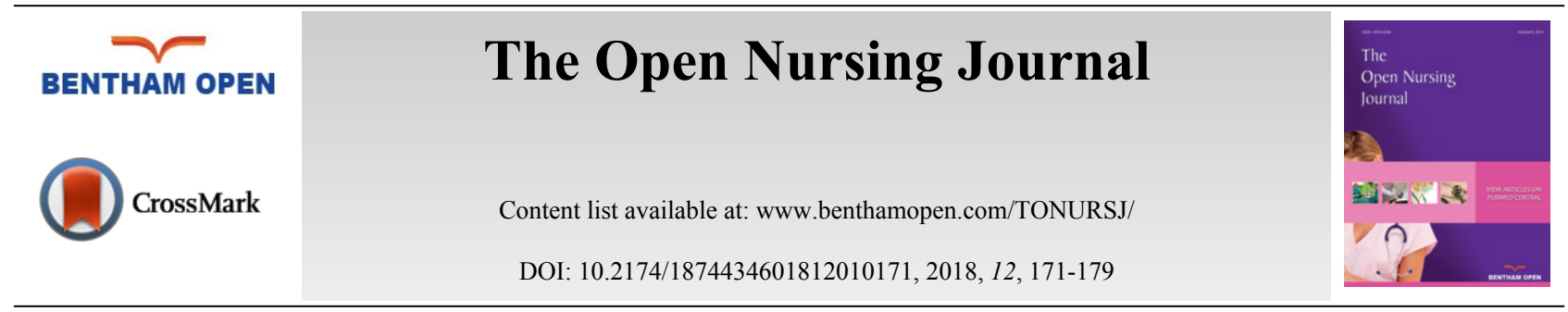

RESEARCH ARTICLE

\title{
Persistent (Anxiety and Depression) Affected Academic Achievement and Absenteeism in Nursing Students
}

\author{
Mohannad Eid Abu Ruz ${ }^{1, *}$, Hekmat Yousef Al-Akash ${ }^{2}$ and Samiha Jarrah ${ }^{3}$ \\ ${ }^{1}$ College of Nursing, Applied Science Private University, Amman, Jordan \\ ${ }^{2}$ Clinical Nursing Department, Applied Science Private University, Amman, Jordan \\ ${ }^{3}$ Faculty of Nursing, Applied Science Private University, Amman, Jordan
}

\begin{abstract}
:
Background:

Anxiety and depression are common among nursing students due to different factors. When they are minimal and not persistent, they work as stimuli for good achievement. However, when they are high or persistent they have negative consequences (i.e. low academic achievement and higher absenteeism rates).
\end{abstract}

\section{Objective:}

The purpose of this study was to check the effect of persistent anxiety and depression on nursing student academic achievement and absenteeism rate.

\section{Methods:}

A prospective observational correlational design with a convenience sample of 170 students enrolled in the undergraduate and graduate programs-college of nursing at a private university in Amman, Jordan. Anxiety and depression were measured twice at the beginning of the semester and then two months later by Hospital Anxiety and Depression Scale. Data regarding grade point average, number of absenteeism and the gender of the students; were collected from the electronic system of the university.

Results:

Persistently anxious group has lower grade point average than persistently non-anxious group (mean [SD], 64.1 [13.8] vs. 73.1 [12.3], $\mathrm{P}<.001)$. Moreover, they have higher absenteeism rate than persistently non-anxious group (7.62 [5.7] vs. 4.0 [3.4], $\mathrm{P}<.001$ ) and higher than transiently anxious group (7.62 [5.7] vs. 4.7 [4.6], $\mathrm{P}<.05)$. Persistently depressed group has lower grade point average than persistently non-depressed group (64.0 [13.8] vs. 73.2 [13.0], $\mathrm{P}<.001)$ and lower than transiently depressed (64.0 [13.8] vs. 71.7 [10.6], $\mathrm{P}<.01)$.

\section{Conclusion:}

Nursing administrators should search for the underlying causes for these negative emotions. Furthermore, setting strategies to control these negative emotions is highly recommended.

Keywords: Anxiety, Depression, Academic achievement, Absenteeism, Collegial life, Education.

\section{INTRODUCTION}

All over the world, nursing students are exposed to multiple challenges during their collegial life [1]. One of these

\footnotetext{
* Address correspondence to this athor at the College of Nursing, Applied Science Private University, P.O Box 142, Shafa Badran, 11934,
} Amman, Jordan, Tel: 00962790262408; Fax: 0096265232899; E-mails: mohannadeid@yahoo.com, m_aburuz@asu.edu.jo 
challenges is vulnerability to emotional instability that may include high levels of anxiety [2 - 8], and depressive symptoms [1, 4, 5, 9 - 11]. However, there is a universal agreement that nursing is a stressful profession and nursing students along with other health care professionals are more likely to experience higher levels of anxiety, stress, and depression than students in other fields [7, 12 - 15].

Specialized literature indicated that nursing students identified multiple and various sources for their anxiety and depression. Some of these sources were considered unique to nursing students such as courses' structure, clinical experiences, and lack of faculty support [16, 17], efforts to meet the academic requirements [13, 14, 17 - 19], hours of work, the nature of the profession such as working with sick persons, and fear of failing their exams [20]. In addition to that, the nature of the nursing program curriculum is considered as a challenging educational experience for most students. The life and death events, and lack of course schedule flexibility places nursing students in susceptible psychological positions.

Students' academic success was linked to their emotional stability [12]. The experienced negative emotional reactions may impact nursing student' academic performance as demonstrated by lower Grade Point Average (GPA) [21 - 23] and student's active attendance to classes. Lower GPAs among nursing students was associated with negative emotional reactions such as anxiety and depression [4, 7]. When nursing students' experienced high levels of stress, it led to more anxiety, anger, and depression. Literature in this field highlighted the consequences of the increased levels of anxiety and depression [24].

This experienced anxiety may also affect their ability to properly prepare for the examination to achieve satisfactory grades in their exam that may lead to low GPA achievements [25]. On the other hand, low GPA achievements may lead to further anxiety, anger, and depression [24], discouragement, absenteeism, and even withdrawal from the college and/or from the profession, impaired role transition, burnout, and poor job performance [26 - 29].

Although research indicated that anxiety and depression exist among nursing students, only minimal research available to clarify that if these two negative emotional impacts are transient (on entry/admission to the college) or persistent (continues over the period of collegial life) [30]. In Jordan, no research exists linking these psychological conditions to GPA and absenteeism at two/several points of their collegial life, at enrollment/Fentry and during study period. Therefore, the purpose of this study was to identify the effects of persistent (depression and anxiety) on the GPA and absenteeism among nursing students. Identification of anxiety and depression levels and their impact among nursing students may help faculty members and education leaders in setting strategies to help students overcome these negative emotional consequences, achieve more satisfactory GPA, and report less absenteeism in their classes. Consequently, higher commitment to nursing, lower withdrawal from the profession, and better patients' care.

\subsection{Research Hypothesis}

Hypothesis 1: Participants who have high anxiety scores at both time points (persistently anxious) will have lower GPA than participants who have high anxiety scores at only one-time point (transiently anxious) or participants who have low anxiety scores at both time points (persistently non-anxious). Hypothesis 2: Participants who are persistently anxious will have higher absenteeism rate than participants who are transiently anxious or participants who are persistently non-anxious. Hypothesis 3: Participants who are persistently depressed will have lower GPA than participants who are transiently depressed or participants who are persistently non-depressed. Hypothesis 4: Patients who are persistently depressed will have higher absenteeism rate than participants who are transiently depressed or participants who are persistently non-depressed.

\section{MATERIALS AND METHODS}

\subsection{Design, Sample, and Setting}

A prospective observational correlational design was used in this study. A convenient sample of all students enrolled in the undergraduate and graduate programs-college of nursing at a private university in Amman, Jordan and agreed to participate was included in the study. The total number of the students enrolled in this college was 300 students; 250 baccalaureate students and 50 master students. The sample consisted of 130 baccalaureate students and 40 master students; response rate $68.0 \%$. Students who have a confirmed diagnosis of anxiety and depression were excluded from the study. To make sure that this sample size was sufficient to get statistical significant difference, power analysis was done using the $\mathrm{G}^{*}$ power software. Statistical test was ANOVA with 3 groups, type 1 error 0.05 , and 
medium effect size of 0.25 , and power of 0.8 . Based on these assumptions, the needed sample size was 159 participants. Therefore, 170 participants were considered enough for the purposes of the analyses.

\subsection{Measurement of Variables}

\subsubsection{Anxiety And Depression}

Anxiety and depression were defined as the total score of the anxiety/depression subscales of Hospital Anxiety and Depression Scale (HADS). This instrument has been chosen because it is short, easy to use and interpret, translated to Arabic, valid, and reliable [31 - 34].

Previous studies tested the psychometric properties of the Arabic version of this instrument [31, 33, 34]. The Cronbach's $\alpha$ reliability coefficients were .78 for anxiety subscale and .87 for the depression subscale indicating a very good internal consistency. Moreover, the anxiety subscale has a high sensitivity and the specificity at $86 \%$ and $87 \%$, respectively [31, 33, 34]. Regarding the depression subscale these were $79 \%$ and $87 \%$, respectively.

The total instrument consists of 14 items in two subscales; one for anxiety and one for depression. Each subscale consists of 7-items that were rated by the participants on a 0 to 3 scale, with 3 indicating higher symptom frequency and severity. The total score for each subscale can range from 0 to 21 , with higher scores indicating higher levels of anxiety/depression.

Previous studies categorized the scores as the following: 0 to 7 , normal; 8 to 10 , mild; 11 to 14 , moderate; and 15 to 21 , severe anxiety/depression [31, 33, 34]. For the purposes of this study, participants were considered nonanxious/non-depressed if they have a score from 0-7, and anxious/depressed if they have a score from 8-21. To avoid categorizing participants who were experiencing transient anxiety/depression as persistently anxious/depressed, anxiety and depression were measured at the beginning of the semester for all students and at two-month follow-up. If the two measures (at the beginning of the semester and at two-month follow-up) were high (from 8-21), the participant was considered as persistently anxious/depressed. If the two measures (at the beginning of the semester and at two-month follow-up) were within normal (from 0-7), the participant was considered as persistently non (anxious/depressed). If one of the measurements was high (from 8-21) and the second was within normal (from 0-7), the participant was considered as transiently anxious/depressed.

\subsubsection{Absenteeism and GPA}

The official semester at Jordanian universities according to academic calendar is composed of 16 weeks. However, the structure of the course is different between the undergraduate and graduate students. For a three credit hours course, the undergraduate students sit three (one-hour) sessions per week for 16 weeks resulting in 48 hours per semester. To meet the needs of the graduate students, the courses are structured differently. The student will sit one (three-hour) session per week for 16 weeks resulting in 48 hours per semester. Therefore, the total hours of absenteeism rate were divided by 48 then it was multiplied by $100 \%$ to get percentages; to avoid the discrepancy in the measurement of absenteeism rate.

To collect the data regarding the GPA, number of absenteeism and the gender of the students; the principal investigator checked the electronic system of the university. Course coordinators upload this information systemically into the system. These information are usually confirmed by the department head and the dean of the college on regular basis each semester which enhance the validity of the data. For the analysis purposes, the absenteeism percentage was divided into three categories as the following: $0-5 \%, 5.1-10 \%$, more than $10 \%$. The GPA is defined as the Grade Point Average of the semester when the study was conducted.

\subsection{Procedure}

The study was approved by the Institutional Review Board committee at Applied Science Private University. The principal investigator met with all students and explained the purpose of the study. Informed consent was obtained at enrollment if the student agreed to participate. Each student completed the HADS at the beginning of the semester and again after 2 months. These two times were chosen to avoid anxiety and depression resulting from examination.

\subsection{Data Analysis}

Data were analyzed using SPSS version 21.0. An alpha of .05 was set a priori. All research hypotheses were checked using ANOVA. When the main model was significant, a post hoc analysis was done using Least Significant 
Difference (LSD) test to determine which group differences were responsible for the significant main effect.

\section{RESULTS}

\subsection{Sample Description}

The sample consisted of 130 undergraduate students and 40 graduate students. Sixty percent of the sample (102 participants) was females. Forty-six participants were persistently depressed, 35 were transiently depressed, and 89 were persistently not depressed. Regarding anxiety, 40 participants were persistently anxious, 30 were transiently anxious, and 100 were persistently not anxious. Fifty eight percent of the sample has absenteeism rate between $0-5 \%$, $26 \%$ of the sample has absenteeism rate between $5.1-10 \%$, and $16 \%$ has absenteeism rate between greater than $10 \%$ (Table 1). There were no differences in any of the characteristics among the three groups.

Table 1. Sample characteristics based on the three levels of anxiety and depression $(\mathrm{N}=170)$.

\begin{tabular}{|c|c|c|c|}
\hline Characteristics & Persistently Anxious (n=40) & Transiently Anxious (n=30) & Non-Anxious (n=100) \\
\hline Age & $26.2 \pm 7.6$ & $25.8 \pm 6.9$ & $26.9 \pm 7.1$ \\
\hline $\begin{array}{c}\text { Gender } \\
\text { Male } \\
\text { Female }\end{array}$ & $17(42.5)$ & $14(46.6)$ & $37(37)$ \\
$16(53.4)$ & $733)$ \\
\hline $\begin{array}{c}\text { Level of Education } \\
\text { Graduate } \\
\text { Undergraduate }\end{array}$ & $23(57.5)$ & $7(23.3)$ & $24(24)$ \\
\hline Characteristics & $9(22.5)$ & $23(76.7)$ & Non-depressed (n=89) \\
\hline Age & $31(77.5)$ & Transiently Depressed (n=35) & $26.7 \pm 6.8$ \\
\hline Gender & Persistently Depressed (n=46) & $25.9 \pm 6.6$ & $34(38.2)$ \\
Male & $26.1 \pm 7.5$ & $10(28.6)$ & $55(61.8)$ \\
\hline Female & $24(52.1)$ & $25(71.4)$ & $13(14.6)$ \\
\hline $\begin{array}{c}\text { Level of Education } \\
\text { Graduate }\end{array}$ & $22(47.9)$ & $15(42.9)$ & $76(85.4)$ \\
\hline Undergraduate & $7(15.2)$ & $20(57.1)$ & \\
\hline
\end{tabular}

Values are Mean $\pm \mathrm{SD}$, or $\mathrm{n}(\%)$.

Table 2. Post hoc analysis for hypotheses testing regarding GPA \& Absenteeism rate.

\begin{tabular}{|c|c|c|c|}
\hline \multicolumn{4}{|c|}{ GPA } \\
\hline Level of Independent Variable & Compared With & Mean Difference & Sig \\
\hline Persistently anxious & Non-anxious & -9.0 & $<.001$ \\
\hline Persistently depressed & Non-depressed & -9.2 & $<.001$ \\
\hline- & Transiently depressed & -7.7 & $<.01$ \\
\hline \multicolumn{4}{|c|}{ Absenteeism rate } \\
\hline Level of Independent variable & Compared with & Mean difference & Sig \\
\hline Persistently anxious & Non-anxious & 3.62 & $<.001$ \\
\hline- & Transiently anxious & 2.92 & $<.05$ \\
\hline Persistently depressed & Non-depressed & 3.52 & $<.001$ \\
\hline- & Transiently depressed & 4.12 & $<.001$ \\
\hline
\end{tabular}

\subsection{Hypotheses Testing: Hypothesis 1}

There was a significant difference in the main model $\left(\mathrm{F}_{(2,167)}=7.62, \mathrm{p}<0.001\right)$. The post hoc analysis showed that the persistently anxious group has lower GPA than persistently non-anxious group (mean [SD], 64.1 [13.8] vs. $73.1[12.3], \mathrm{P}<.001)$. There were no other significant differences in the other comparisons. Hypothesis 2: There was a significant difference in the main model $\left(\mathrm{F}_{(2,167)}=12.67, \mathrm{p}<0.001\right)$. The post hoc analysis showed that the persistently anxious group has higher absenteeism rate than persistently non-anxious group (mean [SD], 7.62 [5.7] vs. 4.0 [3.4], $\mathrm{P}<.001$ ) and higher than transiently anxious group also (mean [SD] 7.62 [5.7] vs. 4.7 [4.6], $\mathrm{P}<.05$ ). There were no other significant differences in the other comparisons. Hypothesis 3: There was a significant difference in the main model $\left(\mathrm{F}_{(2,167)}=7.95, \mathrm{p}<0.001\right)$. The post hoc analysis showed that the persistently depressed group has lower GPA than 
persistently non-depressed group (mean [SD], 64.0 [13.8] vs. 73.2 [13.0], $\mathrm{P}<.001$ ) and lower than transiently depressed (mean [SD], 64.0 [13.8] vs. 71.7 [10.6], $\mathrm{P}<.01$ ). There were no other significant differences in the other comparisons. Hypothesis 4: There was a significant difference in the main model $\left(\mathrm{F}_{(2,167)}=13.55, \mathrm{p}<0.001\right)$. The post hoc analysis showed that the persistently depressed group has higher absenteeism rate than persistently non-depressed group (mean [SD], 7.52 [5.9] vs. 4.0 [3.7], $\mathrm{P}<.001$ ) and higher than transiently depressed (mean [SD], 7.52 [5.9] vs. 3.4 [2.9], $\mathrm{P}<.001)$. There were no other significant differences in the other comparisons (Table 2).

\section{DISCUSSION}

Results of this study showed that persistently anxious and depressed nursing students are more likely to have lower academic achievement as demonstrated by GPA and higher absenteeism rate than transiently non-anxious, nondepressed nursing students. There were no other significant differences in the other comparisons. This study responded to the gap in the literature investigating GPA and absenteeism in the context of anxiety and depression among nursing students at two different points of time. So, discussion of findings from this study will be in the light of other similar conclusions from other healthcare professions.

Several studies identified different levels of anxiety among nursing students at different stages of their collegial life. For example, some studies [28, 35, 36] shared the same conclusions that nursing students' anxiety continues to increase as they go through the program to reach its highest level in their final year of the program. While, others found that nursing students' anxiety was at its highest level during the second year of the program [37]. These conclusions support the existence of different anxiety levels among nursing students along their collegial life. However, there was no linkage of anxiety to academic achievement or absenteeism in any of these studies.

The level of anxiety that nursing students experience can be explained by the progression through the developmental stages of the student [38]. The usual age of collegial life is 18-22 years old, which is the age when young people seek education and training to become successful adults [39]. This achievement is critical to successful adjustment and emotional well-being, while, failure may hinder emotional adjustment. Fear of failure provides a possible explanation for their anxiety [40]. Moreover, collegial age represents transition or bridge between adolescence and adulthood stages of life. This transition may hold some stress that can expose students for poor mental health which can affect their emotional well-being throughout the lifespan [41].

Persistent anxiety and depression are examples of these emotional consequences that may impair their progress in the nursing program [16, 26, 42]. To some extent, the hypotheses of this study, that persistently anxious and depressed students will have lower academic achievement is consistent with these findings as feelings of stress may be experienced during entrance to nursing school as a stage to transition to collegial life [43].

Investigating the literature, mixed results were found. Although no-nursing individuals were subjects of these studies, anxiety can affect learning and academic achievement was determined by overall level of mental health in most of the cases. For example, Yeh, et al. (2007) indicated that individuals with high levels of anxiety had poor academic achievement under stressful instruction and extreme levels of anxiety interferes with their attention [44]. A previous study also showed that extreme anxiety when facing an examination could impair individuals' cognitive function and further impair their performance [45], which give further support to our findings from this study.

However, individuals with low levels of anxiety had better academic achievement under stressful instruction [46]. In one of the reviewed studies on medical student, learning under different levels of anxiety and depression, anxiety and depression follow up gave different directions of correlation (positive and negative) between levels of anxiety and academic achievement [46]. Another example, Yeh, et al. (2007) indicated that appropriate degrees of anxiety, especially concerning fear of failure, would self-reinforce the motivation system, and those with "fear of failure" had better performance in tough tasks than those with "hope of success". Further studies are indicated to set a cutoff point or limits for the appropriate level of anxiety and to investigate the impact of this level among nursing students.

Depression and GPA are interrelated. As depression may impact GPA, in turn, lower GPA may result in Depression. Chen, et al., (2015) in their study of 700 Taiwanese nursing students, they found that depressive symptoms are significantly related to GPA, and, higher levels of depression were observed in students with low GPA, while those with higher GPA were less likely to report depressive symptoms [47]. Additional studies might be indicated to check the reverse impact of academic achievement on emotional wellbeing.

Regarding absenteeism, some studies failed to find a significant correlation between academic achievement and attendance [48 - 51]. However, others supported the hypothesis that absence from the class and the academic 
achievement are correlated. Absenteeism and not being physically available in the class can negatively impact the examination grades as demonstrated by GPA [52 - 56] and considerably lowers the students' final grade (about 2 points in a 0-20-point grading scheme) [57]. In addition, some studies found that attendance was improved when it was tied to grades [58, 59] and a compulsory, though flexible, attendance policy contributes to improving students' academic performance [60]. Further studies are indicated to investigate the impact of various attendance polices on absenteeism and GPA.

\section{CONCLUSION}

Academic achievement is an important dimension for students. It is essential for educational institutions to assist students to develop emotionally as well as academically. This study provided an evidence for the impact of negative emotions such as anxiety and depression upon GPA and absenteeism. Moreover, this study showed that persistent anxiety and depression have a major effect on students' academic achievement and attendance to classes. It is highly recommended that administrators identify different sources of anxiety and depression and set strategies to control these negative emotions. Additionally, formal and periodic referral of students with early signs of anxiety and depressions to the psychosocial counselor should be planned for to detect and manage such symptoms.

\section{LIMITATIONS}

This study was the first one in Jordan to include graduate student. However, the number of the graduate students that were included in this study was small. It is recommended to repeat this study with larger sample size of graduate students and to check the effect of interventions to control anxiety and depression on the outcomes of interest.

\section{ETHICS APPROVAL AND CONSENT TO PARTICIPATE}

The study was approved by the Institutional Review Board committee at Applied Science Private University.

\section{HUMAN AND ANIMAL RIGHTS}

No Animals/Humans were used for studies that are base of this research.

\section{CONSENT FOR PUBLICATION}

Informed consent was obtained at enrollment if the student agreed to participate.

\section{CONFLICT OF INTEREST}

The authors declare no conflict of interest, financial or otherwise.

\section{ACKNOWLEDGEMENTS}

The authors are grateful to Applied Science Private University, Amman, Jordan, for the partial financial support granted to this research project, and the financial support granted to cover the publication fees of this research article.

\section{REFERENCES}

[1] Rathnayake S, Ekanayaka J. Depression, anxiety and stress among undergraduate nursing students in public university in Sri Lanka. Int J Car Sci 2016; 9(3): 1020-32.

[2] Gibbons C, Dempster M, Moutray M. Stress, coping and satisfaction in nursing students. J Adv Nurs 2011; 67(3): 621-32. [http://dx.doi.org/10.1111/j.1365-2648.2010.05495.x] [PMID: 21077931]

[3] Reeve KL, Shumaker CJ, Yearwood EL, Crowell NA, Riley JB. Perceived stress and social support in undergraduate nursing students' educational experiences. Nurse Educ Today 2013; 33(4): 419-24.

[http://dx.doi.org/10.1016/j.nedt.2012.11.009] [PMID: 23246284]

[4] Chen CJ, Chen YC, Sung HC, Hsieh TC, Lee MS, Chang CY. The prevalence and related factors of depressive symptoms among junior college nursing students: A cross-sectional study. J Psychiatr Ment Health Nurs 2015; 22(8): 590-8. [http://dx.doi.org/10.1111/jpm.12252] [PMID: 26149070]

[5] Cheung T. Depression, anxiety and symptoms of stress among baccalaureate nursing students in hong kong: A cross-sectional study. Int J Environ Res Pub Health 2016; 13(8)

[6] Cheung T, Yip PS. Depression, anxiety and symptoms of stress among hong kong nurses: A cross-sectional study. Int J Environ Res Public Health $2015 ; 12(9): 11072-100$. [http://dx.doi.org/10.3390/ijerph120911072] [PMID: 26371020] 
[7] Wedgeworth M. Anxiety and education: An examination of anxiety across a nursing program. J Nurs Educ Pract 2016; 6(10) [http://dx.doi.org/10.5430/jnep.v6n10p23]

[8] Gibbons C, Dempster M, Moutray M. Stress, coping and satisfaction in nursing students. J Adv Nurs 2011; 67(3): 621-32. [http://dx.doi.org/10.1111/j.1365-2648.2010.05495.x] [PMID: 21077931]

[9] Papazisis G, Nicolaou P, Tsiga E, Christoforou T, Sapountzi-Krepia D. Religious and spiritual beliefs, self-esteem, anxiety, and depression among nursing students. Nurs Health Sci 2014; 16(2): 232-8. [http://dx.doi.org/10.1111/nhs.12093] [PMID: 24102942]

[10] Buchanan JL. Prevention of depression in the college student population: A review of the literature. Arch Psychiatr Nurs 2012; 26(1): 21-42. [http://dx.doi.org/10.1016/j.apnu.2011.03.003] [PMID: 22284078]

[11] Papazisis G, Tsiga E, Papanikolaou N, Vlasiadis I, Sapountzi-Krepia D. Psychological distress, anxiety and depression among nursing students in Greece. Int J Caring Sci 2008; 1(1): 42-6.

[12] Wedgeworth MG. A cross-sectional analysis of state trait anxiety among pre, early, and late baccalaureate nursing students: Implicat Nursing Educat 2013.

[13] Driscoll RE. High test anxiety among nursing students. 2009. Available from: https: //eric.ed.gov/?id=ED506526 cited 2017 Oct/1/2017

[14] Edelman M, Ficorelli C. A measure of success: nursing students and test anxiety. J Nurses Staff Dev 2005; 21(2): 55-9. [http://dx.doi.org/10.1097/00124645-200503000-00004] [PMID: 15812275]

[15] Murphy JG, McDevitt-Murphy ME, Barnett NP. Drink and be merry? Gender, life satisfaction, and alcohol consumption among college students. Psychol Addict Behav 2005; 19(2): 184-91. [http://dx.doi.org/10.1037/0893-164X.19.2.184] [PMID: 16011389]

[16] Melo K, Williams B, Ross C. The impact of nursing curricula on clinical practice anxiety. Nurse Educ Today 2010; 30(8): 773-8. [http://dx.doi.org/10.1016/j.nedt.2010.02.006] [PMID: 20381219]

[17] Nursing AAoCo. Nursing shortage fact sheet. 2012. Available from: https: //www.lwtech.edu/about/foundation/ raisebsnup/docs/nursingshortage- fact-sheet.pdf cited 2017 Oct/2/2017

[18] Brewer T. Test-taking anxiety among nursing \& general college students. J Psychosoc Nurs Ment Health Serv 2002; 40(11): 22-9. [PMID: 12448036]

[19] Sharif F, Armitage P. The effect of psychological and educational counselling in reducing anxiety in nursing students. J Psychiatr Ment Health Nurs 2004; 11(4): 386-92.

[http://dx.doi.org/10.1111/j.1365-2850.2003.00720.x] [PMID: 15255911]

[20] Reese KMKRJ. Measurement of test and study worry and emotionality in college students a psychometric evaluation of the test and study attitudes inventory. Edu Psychol Measure 2009; 69(2): 303-21.

[http://dx.doi.org/10.1177/0013164408323231]

[21] Chernomas WM, Shapiro C. Stress, depression, and anxiety among undergraduate nursing students. Int J Nurs Educ Scholarsh 2013; 10(1): 255-66. [http://dx.doi.org/10.1515/ijnes-2012-0032] [PMID: 24200536]

[22] Sreeramareddy CT, Shankar PR, Binu VS, Mukhopadhyay C, Ray B, Menezes RG. Psychological morbidity, sources of stress and coping strategies among undergraduate medical students of Nepal. BMC Medical Edu 2007; 7(26) [http://dx.doi.org/10.1186/1472-6920-7-26]

[23] Uras C, Delle Poggi A, Rocco G, Tabolli S. Psychological wellbeing and risk of anxiety/depression in nursing students measured with the General Health Questionnaire-12. Assist Inferm Ric 2012; 31(2): 70-5. [PMID: 22825294]

[24] Rosenthal BS, Schreiner AC. Prevalence of psychological symptoms among undergraduate students in an ethnically diverse urban public college. J Am Coll Health 2000; 49(1): 12-8. [http://dx.doi.org/10.1080/07448480009596277] [PMID: 10967879]

[25] Poorman SG, Mastorovich ML, Molcan KL, Liberto L. Consultants N. Good thinking: Test taking and study skills. $3^{\text {rd }}$ ed. PA 2011.

[26] Duchscher JE. Transition shock: The initial stage of role adaptation for newly graduated registered nurses. J Adv Nurs 2009; 65(5): 1103-13. [http://dx.doi.org/10.1111/j.1365-2648.2008.04898.x] [PMID: 19183235]

[27] Laschinger HK, Finegan J, Wilk P. New graduate burnout: The impact of professional practice environment, workplace civility, and empowerment. Nurs Econ 2009; 27(6): 377-83.

[PMID: 20050488]

[28] Rella S, Winwood PC, Lushington K. When does nursing burnout begin? An investigation of the fatigue experience of Australian nursing students. J Nurs Manag 2009; 17(7): 886-97. [http://dx.doi.org/10.1111/j.1365-2834.2008.00883.x] [PMID: 19793246]

[29] Unruh LY, Nooney J. Newly licensed registered nurses' perceptions of job difficulties, demands and control: Individual and organizational predictors. J Nurs Manag 2011; 19(5): 572-84. [http://dx.doi.org/10.1111/j.1365-2834.2011.01239.x] [PMID: 21749531] 
[30] Floyd. Depression, Anxiety, and Stress Among Nursing Students and the Relationship to Grade Point Average. 2010.

[31] el-Rufaie OE, Absood GH. Retesting the validity of the arabic version of the Hospital Anxiety and Depression (HAD) scale in primary health care. Soc Psychiatry Psychiatr Epidemiol 1995; 30(1): 26-31. [http://dx.doi.org/10.1007/BF00784431] [PMID: 7892615]

[32] Bjelland I, Dahl AA, Haug TT, Neckelmann D. The validity of the hospital anxiety and depression scale. An updated literature review. J Psychosom Res 2002; 52(2): 69-77.

[http://dx.doi.org/10.1016/S0022-3999(01)00296-3] [PMID: 11832252]

[33] Al Aseri ZA, Suriya MO, Hassan HA, et al. Reliability and validity of the Hospital Anxiety and depression scale in an emergency department in Saudi Arabia: A cross-sectional observational study. BMC Emerg Med 2015; 15: 28. [http://dx.doi.org/10.1186/s12873-015-0051-4] [PMID: 26459412]

[34] el-Rufaie OE, Absood G. Validity study of the hospital anxiety and depression scale among a group of saudi patients. Br J Psychiatry 1987; 151: $687-8$. [http://dx.doi.org/10.1192/bjp.151.5.687] [PMID: 3446314]

[35] Suresh P, Matthews A, Coyne I. Stress and stressors in the clinical environment: A comparative study of fourth-year student nurses and newly qualified general nurses in Ireland. J Clin Nurs 2013; 22(5-6): 770-9. [PMID: 22931367]

[36] Timmins F, Corroon AM, Byrne G, Mooney B. The challenge of contemporary nurse education programmes. Perceived stressors of nursing students: Mental health and related lifestyle issues. J Psychiatr Ment Health Nurs 2011; 18(9): 758-66. [http://dx.doi.org/10.1111/j.1365-2850.2011.01780.x] [PMID: 21985678]

[37] Jimenez C, Navia-Osorio PM, Diaz CV. Stress and health in novice and experienced nursing students. J Adv Nurs 2010; 66(2): $442-55$. [http://dx.doi.org/10.1111/j.1365-2648.2009.05183.x] [PMID: 20423427]

[38] Erikson E, Ed. Identity, youth, and crisis. New York: Norton 1968.

[39] Arnett JJ. Emerging adulthood. A theory of development from the late teens through the twenties. Am Psychol 2000; 55(5): 469-80. [http://dx.doi.org/10.1037/0003-066X.55.5.469] [PMID: 10842426]

[40] Stringer K, Kerpelman J, Skorikov V. A longitudinal examination of career preparation and adjustment during the transition from high school. Dev Psychol 2012; 48(5): 1343-54. [http://dx.doi.org/10.1037/a0027296] [PMID: 22329383]

[41] Lee C, Gramotnev H. Life transitions and mental health in a national cohort of young australian women. Dev Psychol 2007; 43(4): 877-88. [http://dx.doi.org/10.1037/0012-1649.43.4.877] [PMID: 17605521]

[42] Cheung RY, Au TK. Nursing students' anxiety and clinical performance. J Nurs Educ 2011; 50(5): 286-9. [http://dx.doi.org/10.3928/01484834-20110131-08] [PMID: 21323251]

[43] DeBerard S, Spielmans G, Julka D. Predictors of academic achievement and retention among college freshmen: A longitudinal study. Coll Stud J 2004; 38(1): 66-81.

[44] Sarason E, Ed. Anxiety and self-preoccupation. New York: Hemisphere 1975.

[45] Comunian AL. Anxiety, cognitive interference, and school performance of Italian children. Psychol Rep 1993; 73(3 Pt 1): 747-54. [http://dx.doi.org/10.2466/pr0.1993.73.3.747] [PMID: 8302981]

[46] Yeh YC, Yen CF, Lai CS, Huang CH, Liu KM, Huang IT. Correlations between academic achievement and anxiety and depression in medical students experiencing integrated curriculum reform. Kaohsiung J Med Sci 2007; 23(8): 379-86. [http://dx.doi.org/10.1016/S0257-5655(07)70001-9] [PMID: 17666304]

[47] Vogel JS, Hurford DP, Smith JV, Cole A. The relationship between depression and smoking in adolescents. Adolescence 2003; 38(149): 57-74. [PMID: 12803454]

[48] Gal B, Busturia I, Garrido C. To be or not to be: The importance of attendance in integrated physiology teaching using non-traditional approaches. BMC Res Notes 2011; 4(360): 360. [http://dx.doi.org/10.1186/1756-0500-4-360] [PMID: 21917181]

[49] Golding. The role of attendance in lecture classes: You can lead a horse to water. Teach Psychol 2011; 38(1): 40-2. [http://dx.doi.org/10.1177/0098628310390915]

[50] Paredes RD. Should students be allowed to miss? J Educ Res 2011; 104(3): 194-201. [http://dx.doi.org/10.1080/00220671003690130]

[51] YU D. How much do study habits, skills, and attitudes affect student performance in introductory college accounting courses? New Horizons Educ 2011; 59(3): 1-15.

[52] Abu Ruz M. Does excessive absence from the class lead to lower levels of academic achievement? Eur Sci J $2015 ; 11$.

[53] Chilwant K. Effect of class attendance on performance in examination in second year medical students. J Res Method Educat 2013; 3(33): 31-3. 
[54] Smith LB. Medical school and on-line learning: does optional attendance create absentee doctors? Med Educ 2012; 46(2): 137-8. [http://dx.doi.org/10.1111/j.1365-2923.2011.04182.x] [PMID: 22239325]

[55] Millis RM, Dyson S, Cannon D. Association of classroom participation and examination performance in a first-year medical school course. Adv Physiol Educ 2009; 33(3): 139-43.

[http://dx.doi.org/10.1152/advan.00028.2009] [PMID: 19745038]

[56] Moonie S, Sterling DA, Figgs LW, Castro M. The relationship between school absence, academic performance, and asthma status. J Sch Health 2008; 78(3): 140-8. [http://dx.doi.org/10.1111/j.1746-1561.2007.00276.x] [PMID: 18307609]

[57] Aurora T. The impact of class absenteeism on undergraduates' academic performance: Evidence from an elite economics school in portugal. Innov Educ Teach Int 2016; 53(2): 230-42. [http://dx.doi.org/10.1080/14703297.2014.937730]

[58] Friedman P, Rodriguez F, McComb J. Why students do and do not attend classes: Myths and realities. Coll Teach 2001; 49: 124-33. [http://dx.doi.org/10.1080/87567555.2001.10844593]

[59] Launius M. College student attendance: Attitudes and academic performance. Coll Stud J 1997; $31:$ 86-92.

[60] Aurora T. The impact of class absenteeism on undergraduates' academic performance: Evidence from an elite economics school in Portugal. Innov Educ Teach Int 2016; 53(2): 230-42. [http://dx.doi.org/10.1080/14703297.2014.937730]

\section{(C) 2018 Abu Ruz et al.}

This is an open access article distributed under the terms of the Creative Commons Attribution 4.0 International Public License (CC-BY 4.0), a copy of which is available at: https://creativecommons.org/licenses/by/4.0/legalcode. This license permits unrestricted use, distribution, and reproduction in any medium, provided the original author and source are credited. 